\title{
Bibliometric Analysis of digitization business economy
}

\author{
Chung-Lien Pan ${ }^{1 *}$ JiaRong Lin ${ }^{1}$, YiHua Wang ${ }^{1}$, ZhiXiang Zhou ${ }^{1}$,YiJiao MO ${ }^{1}$ \\ ${ }^{1}$ Nanfang College of Sun Yat-sen University School of Accounting Guangzhou, Guangdong
}

\begin{abstract}
Digital technology is being applied by different organizations, for example, the sharing economy, blockchain, and other topics are very popular in recent years, which leads to obvious changes in different fields. At the same time, there is growing interest in the digital business economy. However, there is less bibliometrics on the subject, and this is a good solution for addressing the opportunities and risks of digital transformation. Based on 731 articles retrieved from the Web of Science (Wos) database between 2000 and 2020, the study reviewed the literature on "ICT industry", "digital economy", "economic analysis" and "market research". Since 2015, publications have experienced rapid growth in several disciplines, such as management, business, economics, library and information science, business economics, etc. At the same time, research institutions in Germany, the United States, and Sweden have performed well in this field. Using this database, the author analyzed what happened and made a concise keyword map to clearly show the connections among the topics based on the co-occurrence network generated by the keyword data. This paper provides a reference point for researchers, funding agencies, policymakers, and industry professionals to study the progress of the digital business economy.
\end{abstract}

\section{INTRODUCTION}

In the context of globalization and digitalization, the digital transformation of business is becoming an inevitable trend [1]. The Internet and digitalization are fundamentally changing and subverting the traditional operation mode of companies [2], which brings great possibilities and major threats to emerging enterprises and existing enterprises [3]. On the one hand, the digital trend has created a new form of knowledge that goes to the heart of innovation and provides the opportunity for the enterprise, to excavate potential has not been developed $[4,5]$. On the other hand, how to deal with the opportunities and risks of digital transformation is a challenge for CIOs (Chief Information Officers) and other senior executives [6].

This study summarizes the research results of business and digitalization in specific fields such as the science of artificial, business and society, multi-sided platform, retailing and sharing economy. For a systematic review, this paper provides a scientific econometric analysis of the subject, drawing important countries, publications, institutions and topics for major research based on a WoS database.

\section{DATA AND METHODS}

This paper aims to provide a literature review on the topic of the "digital business economy". For the purpose of obtaining the relevant literature of commercial digitization, the undergraduate metrology analysis first collects the literature from the WoS, and the query is deployed as follows:

$\mathrm{TS}=$ ("digitalization" OR "digital transformation") AND $\mathrm{SU}=$ ("Business \& Economics" OR WC= (Business OR "Business, finance" ) )

By February 2020, about 731 articles (including sciexpanded, SSCI, A\&HCI, ESCI) were retrieved. And mapping using VOSviewer and Python visualization packages for exploratory analysis.

\section{PRESEARCH FINDINGS}

This study explores how research on the digital transformation of business has been conducted to date in terms of major countries, publications, institutions, and themes.

\section{A. Annual trends}

As shown in figure 1 and figure 2, both publications and citations on this topic have increased sharply since 2015. At the same time, we can notice that from 2010 to 2015, the citation trend of this topic has been rising slowly, and after 2015, it has been rising exponentially.

*Corresponding author. Email: peter5612@gmail.com 


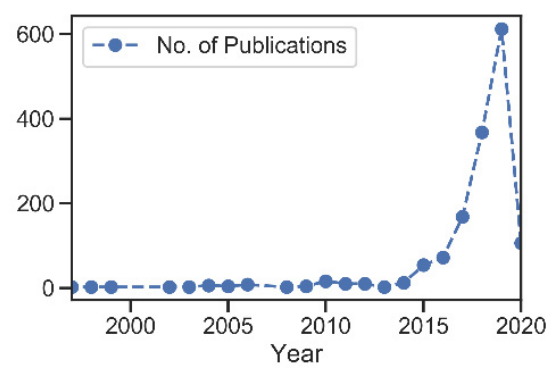

Figure1. The number of publications

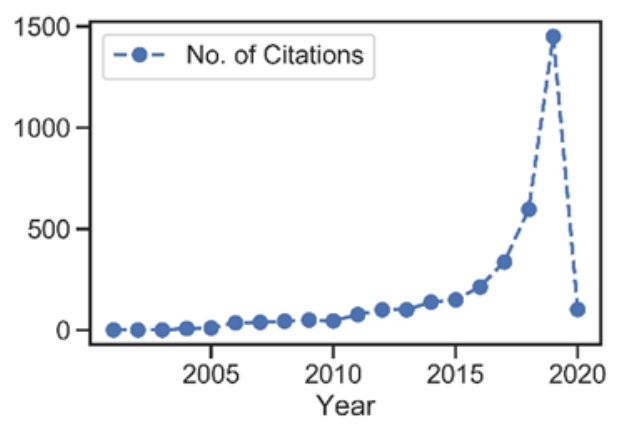

Figure2. The number of citations

\section{B. WOS categories and research areas}

A list of the top WoS categories is given in table 1, with management, business, and economics in the top three. The first three categories account for two-thirds of the total number of publications, indicating the advantages of management, business, and economicrelated research areas on the subject.

TABLE I. Top 5 WOS CATEGORIES

\begin{tabular}{|l|l|}
\hline WoS & \% \\
\hline Management & $32.22 \% \%$ \\
\hline Business & $26.26 \%$ \\
\hline The economy & $14.44 \%$ \\
\hline Library and information science & $3.61 \%$ \\
\hline Business and economics & $3.07 \%$ \\
\hline
\end{tabular}

Table 2 lists the top 5 hot research areas, roughly the same as the WoS categories. We need to pay special attention to the area of business and economics, the data show that the number of published papers in this field accounts for $76.89 \%$ of the total.

TABLE II. TOP RESEARCH AREA

\begin{tabular}{|l|l|}
\hline Research Area & \% \\
\hline Business \& Economics & $76.89 \%$ \\
\hline Information Science \& Library Science & $4.20 \%$ \\
\hline Engineering & $3.36 \%$ \\
\hline Public Administration & $2.94 \%$ \\
\hline Computer Science & $2.84 \%$ \\
\hline
\end{tabular}

\section{Top published countries}

From figure 3, we can find that the literature mainly comes from developed countries such as North America and Europe. The data show that Germany has a significant influence in this area of research, followed by the United States and Sweden.

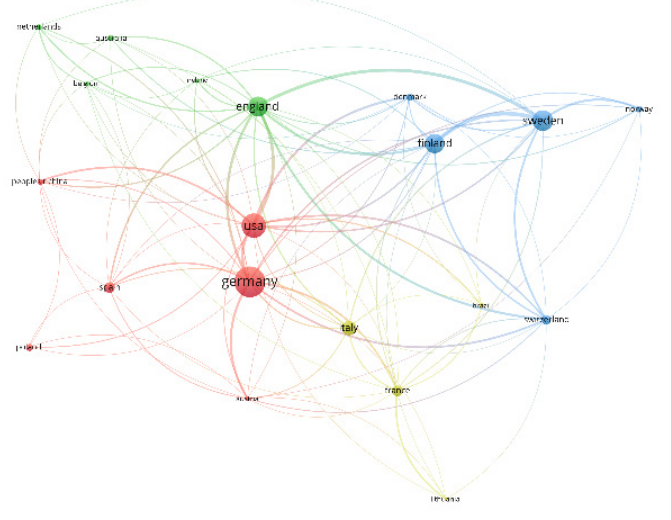

Figure3. Top published countries

Table 3 and Table 4 list the top 5 institutions and funding agencies and provide detailed information on the geographical distribution of research institutions. Sweden plays an important role in this field. The Lulea University of Technology, University of Gothenburg and Chalmers University of technology are all universities in Sweden. while in the top five, the top two were from Russia and the European Union, with Sweden accounting for two-fifths (the Swedish research council, Swedish retail and wholesale council).

Also, the National Natural Science Foundation of China (NSFC), which is part of China, ranks third in the world in investment in this field, but the research results have yet to be revealed.

TABLE III. TOP INSTITUTIONS

\begin{tabular}{|l|l|}
\hline Institutions & No. of Articles \\
\hline Lulea University of Technology & 12 \\
\hline Russian Academy of Science S & 12 \\
\hline University of Gothenburg & 12 \\
\hline Aalto University & 11 \\
\hline Chalmers University of Technology & 11 \\
\hline
\end{tabular}

Table IV. TOP FUNDING AGENCIES

\begin{tabular}{|l|l|}
\hline Funding Agencies & $\begin{array}{l}\text { No. of } \\
\text { Articles }\end{array}$ \\
\hline Russian Foundation for Basic Research (RFBR) & 11 \\
\hline European Union (EU) & 9 \\
\hline National Natural Science Foundation of China & 7 \\
\hline Swedish Research Council & 5 \\
\hline Swedish Retail and Wholesale Council & 4 \\
\hline
\end{tabular}




\section{Analysis author keywords}

To explore the way concepts and topics are clustered, figure 4 shows the co-occurrence network of author keywords. We identify 5 clusters. The cluster a (big data and data applications) includes keywords such as "CRM(customer relationship management)"," DLT( Distributed ledger technology)"," AI(Artificial Intelligence )"," machine learning ", widely used in business models such as sharing economy, blockchain, supply chain finance (SCF).

Clusters b (digital transformation and enterprise) include " small and medium enterprises "," innovation "," entrepreneurship "," dynamic capabilities ", as mentioned in the literature, the emergence of digital technology has changed innovation and entrepreneurship, and also has a wide impact on the creation and acquisition of value ${ }^{[7]}$. The rise of digital technology has aroused the enthusiasm of many entrepreneurs and the transformation of small and small and medium enterprises.

Cluster c (sharing economy) consists of "sharing economy "," sustainability "," digital platform" and so on. It represents the birth of many digital platforms in the current wave of the active sharing economy, for example, Didi Taxi, Airbnb and other enterprises, they are all working towards sustainable development.

Clusters d (business models and their improvements) have topics such as "business models "," services "," value creation ", and cluster $\mathrm{d}$ and $\mathrm{c}$ are closely linked according to figure 4 . It shows that the modern business model is closely linked to the development of the sharing economy and digital platform, creating a new blue sea strategy.

Cluster e (digitization) covers topics such as "information and communication technology (ICT industry)"," digital economy "," globalization "," market research ", etc., digital research is connected with emerging star industries, especially in the commercial economy.

The key diagram clearly shows that the impact of digital technology on the business economy cannot be underestimated, it promotes entrepreneurship and innovation and also promotes the rise and rise of the new commercial economy, such as sharing economy, supply chain finance and so on.

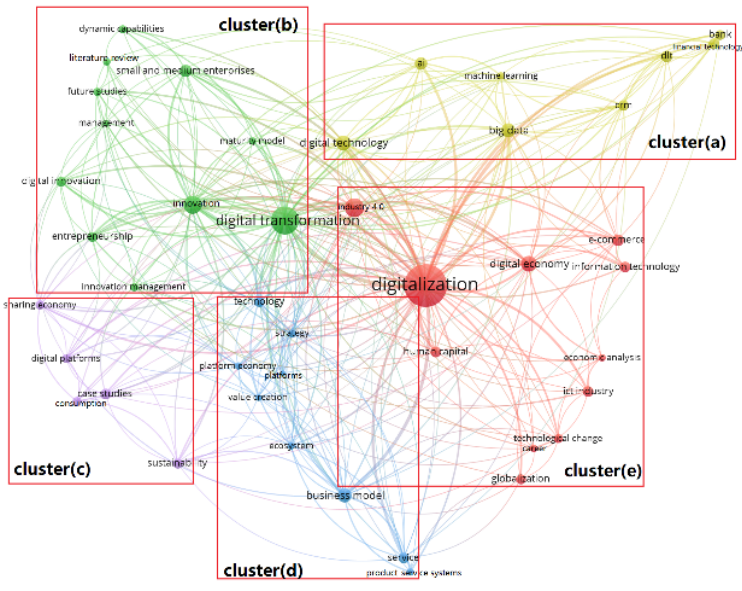

Figure 4 A map based on bibliographic keyword co-occurrence (author keywords)

\section{E. Main sources and disciplines}

To identify the research frontier of the "digital business economy", this paper presents cluster analysis and visualization of top publications and top referral sources.

As shown in Figure 5, the top journals that have published relevant papers include "Technological Forecasting and Social Change", "Technology Innovation Management Review" and "Quality-access to Success". Based on the Wos categories (field tag: WC), the first is the interdisciplinary subject of Business and Regional \& Urban Planning, and the second and third are Management subjects.

In addition, the interdisciplinary subjects of Economics and Information Science \& Library Science are also popular publications, such as "Terra Economicus" and "MIS Quarterly Executive". On the other hand, the disciplines of Industrial Relations \& Labor and Engineering \& Industrial are also in the top 20, including "Transfer European Review of Labour and Research" and "Research-Technology Management".

On the contrary, there are few publications in the Retail Industry, which are located on the periphery of the bibliographic coupling relationship network, contrary to the main disciplines of Business and Management.

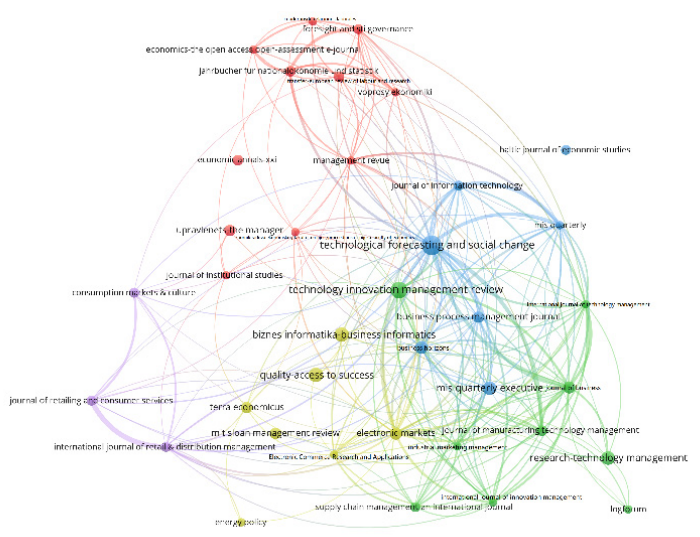

Figure 5 Top publication sources: a bibliographic coupling relationship network visualization 


\section{CONCLUSION}

This research has carried on the analysis to the digital commercial economy this domain topic, the scientific metrology analysis result shows: (1) Since 2015, the digital business economy has seen a rapid increase in the number of publications and citations, of which Germany, the United States, and Sweden play an important role ; (2) Research in developing countries in this field is still in its infancy; (3) the main research contents include(a) The impact and application of digital transformation in business, (b) digital technology promotes entrepreneurship and innovation, and (c) AI, machine learning and other high-tech business value creation.

In future research, the research of the digital business economy should combine more themes such as consumer retail, production service, and digital product innovation, to promote the healthy and sustainable development of digital business economy, improve the innovation ability of enterprises and enhance the competitiveness of enterprises. On the other hand, this research also found that the literature on this topic also includes such interesting topics as "political corporate social responsibility (PCSR)", the music industry and resource conservation. To make a more effective development of this topic, we must pay attention to the emergence and development of such emerging empirical research. Also, the digital divide in national and geographical areas is a problem that needs attention, which will limit and threaten the research and application of digital commerce.
It is true that digital technology is driving disruptive innovation in its own way. However, when the business economy uses such technologies for transformation, it is essential to consider sustainability, what impacts will have on society and how governments and their policies should respond.

\section{REFERENCES}

[1] Hagberg J, Sundstrom M, Egels-Zandén N. The digitalization of retailing: an exploratory framework[J]. International Journal of Retail \& Distribution Management, 2016, 44(7): 694-712.

[2] Karimi J, Walter Z. The Role of Dynamic Capabilities in Responding to Digital Disruption: A Factor-Based Study of the Newspaper Industry[J]. Journal of Management Information Systems, 2015, 32(1): 39-81.

[3] Kathan W, Matzler K, Veider V. The sharing economy: Your business model's friend or foe?[J]. Business Horizons, 2016, 59(6): 663-672.

[4] Lerch C, Gotsch M. Digitalized Product-Service Systems in Manufacturing Firms: A Case Study Analysis[J]. ResearchTechnology Management, 2015.

[5] Dougherty D, Dunne D D. Digital Science and Knowledge Boundaries in Complex Innovation[J]. Organization Science, 2012, 23.

[6] Hess T, Matt C, Benlian A, Wiesboeck F. Options for Formulating a Digital Transformation Strategy[J]. MIS Quarterly Executive: A Research Journal Dedicated to Improving Practice, 2016.

[7] Roth S. Digital Transformation of Social Theory. A Research Update[J]. SSRN Electronic Journal, 2019. 